\title{
Spectral analysis of 10-m resolution temperature profiles from balloon soundings over Beijing
}

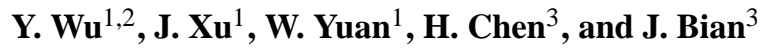 \\ ${ }^{1}$ State Key Laboratory for Space Weather, Center for Space Science and Applied Research, Chinese Academy of Sciences, \\ P.O. Box 8701, Beijing 100080, China \\ ${ }^{2}$ School of Electronic Information, Wuhan University, China \\ ${ }^{3}$ LAGEO, Institute of Atmospheric Physics, Chinese Academy of Sciences, Beijing 100029, China
}

Received: 20 February 2006 - Revised: 29 May 2006 - Accepted: 6 June 2006 - Published: 9 August 2006

\begin{abstract}
Vertical temperature profiles with a height resolution of $10 \mathrm{~m}$ have been measured in the troposphere and lower stratosphere during March and April 2003 over the Beijing Meteorological Observatory. This resolution allows us to study temperature spectra up to higher wave numbers than many published papers. Our purposes in this study are to examine the spectral character of normalized temperature fluctuations in the $2.90-8.01 \mathrm{~km}$ (troposphere) and 14.65$19.76 \mathrm{~km}$ (lower stratosphere) altitude ranges and to compare them with model spectra. Vertical wave number spectra of six temperature profiles are presented. Results indicate that mean spectral slopes are about -1.9 in the troposphere and -2.2 in the lower stratosphere, which is believed to be the shallowest slopes ever measured by balloonborne radiosonde soundings. Mean spectral amplitudes at $m=1 /(100 \mathrm{~m})$ are about 17 times larger in the troposphere and 4 times larger in the lower stratosphere than the predicted saturated spectral amplitudes. These results show that the observed temperature spectra do not obey current gravity wave saturation models, the "universal" atmospheric spectrum model, or the wind-shifting model, in both slope and amplitude.
\end{abstract}

Keywords. Meteorology and atmospheric dynamics (Middle atmosphere dynamics; Waves and tides; Instruments and techniques)

\section{Introduction}

Mesoscale wind and temperature fluctuations are conveniently described in terms of their power spectra versus frequency and horizontal and vertical wave number. In the early 1980s, VanZandt (1982) pointed out that the observed vertical wave number spectra in the troposphere and lower

Correspondence to: $\mathrm{Y}$. Wu

(yfwu@ns.spaceweather.ac.cn) stratosphere tend to have the same shape and power spectral density, regardless of season, meteorological conditions, and geographical location. He called this a "universal" spectrum, following the terminology for the same phenomenon in the ocean (Garrett and Munk, 1975). Motivated by observations of the "universal" spectrum, Dewan and Good (1986) developed a model in terms of saturation, due to linear instability of gravity waves. Subsequently, Smith et al. (1987) extended this model, whereas Weinstock (1990), Hines (1991), Gardner (1994), and Dewan (1997) proposed the nonlinear wave diffusion model, Doppler-spread model, diffusive filtering model, and saturated-cascade model, respectively.

A variety of observational techniques have been used to study mesoscale fluctuations in different atmospheric regions, including Jimsphere balloon observations (Endlich et al., 1969), MST and MU radar measurements (Fritts and Chou, 1987; Tsuda et al., 1989); rocket smoke trail observations (Dewan et al., 1984), and lidar measurements (Senft and Gardner, 1991; Senft et al., 1993). These observational studies have revealed a considerable degree of universality of spectral shape and consistency with predictions of various saturation models.

Balloon radiosonde soundings provide another potentially important source of information about gravity wave spectra in the troposphere and lower stratosphere (Fritts et al., 1988; Tsuda et al., 1991; Allen and Vincent, 1995; Nastrom et al., 1997; Pfenninger et al., 1999; and Nastrom and VanZandt, 2001). Recently, the Beijing Meteorological Observatory $\left(39^{\circ} 48^{\prime} \mathrm{N}, 116^{\circ} 28^{\prime} \mathrm{E}\right)$ began routinely recording and archiving high-resolution data from GPS radiosondes, with pressure, temperature and relative humidity measurements made every $1 \sim 2 \mathrm{~s}$, or about $5 \sim 10 \mathrm{~m}$ intervals. These observations are ideal for investigations of power spectra in the troposphere and lower stratosphere. The details of the high resolution measurements are described elsewhere (Bian et al., 2005).

Published by Copernicus GmbH on behalf of the European Geosciences Union. 

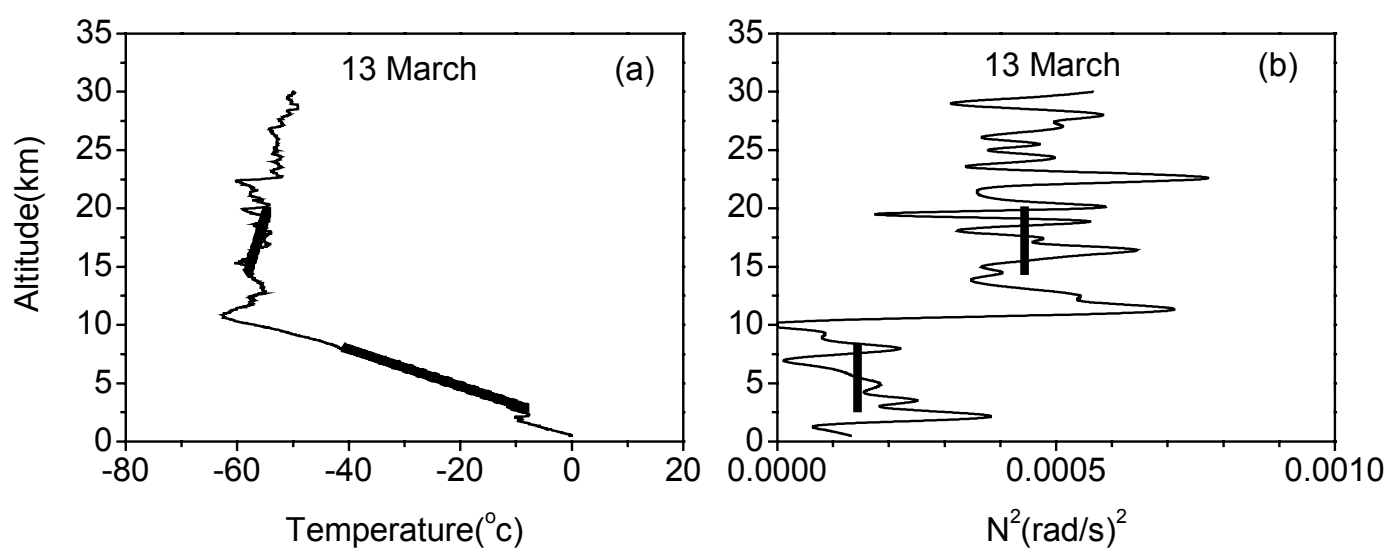

Fig. 1. An example of temperature (a) and $N^{2}$ (b) profiles observed on 13 March 2003 during the balloon ascent. The solid lines on the temperature profile show the linear background profiles. Vertical bars on the $N^{2}$ profile show the mean values of $N^{2}$ and the height ranges used in spectral calculations.

Although numerous papers have been published describing the statistical characteristics of the vertical wave number spectra of the normalized temperature fluctuations, nearly all of these previous studies used the temperature data with height resolutions of 150-20 m. Very little information about temperature spectra with a height resolution of $10 \mathrm{~m} \mathrm{ob-}$ served by radiosondes is currently available. Furthermore, the significance of high resolution vertical profiles of wind and temperature has been widely recognized (Dewan et al., 1984; Barat and Cot, 1992; Wu and Widdel, 1992; de la Torre et al., 1997 and Bian et al., 2005), and is more important in the high wave number region of the spectra.

In this study, we utilize the temperature data to examine spectral characteristics of normalized temperature fluctuations in the 2.90-8.01 km (troposphere) and 14.65-19.76 km (lower stratosphere) altitude ranges and to compare them with model spectra. However, during the course of this study it became clear that our observed spectra do not obey current gravity wave saturation models, the "universal" atmospheric spectrum model, or the wind-shifting model. These discrepancies are discussed in detail in this paper.

\section{Method of data analysis}

The Beijing Meteorological Observatory developed a highresolution GPS balloon sounding system in 2001. The system measures the pressure, temperature, and humidity, etc., at $1 \sim 2$-s or $5 \sim 10$-m height intervals. In this study we analyze only the temperature data obtained at $1-\mathrm{s}$ or $5-\mathrm{m}$ height intervals during the balloon ascent. The temperature data are interpolated at 5-m height intervals using a cubic spline function, in order to obtain equally spaced data points, and then the resulting temperature profiles are further averaged over $10 \mathrm{~m}$, to increase confidence in the temperature estimates. Thus, the final temperature profiles have a height resolution of $10 \mathrm{~m}$. The $10-\mathrm{m}$ resolution allows us to study temperature spectra up to higher wave numbers than many published papers. Since the accuracy of each temperature measurement is $0.1^{\circ} \mathrm{C}$, the accuracy of the final profiles becomes about $0.07^{\circ} \mathrm{C}$.

Although the temperature profiles are also observed during the balloon descent, they are not used in our analysis. The principal reason for this is that Gardner and Gardner (1993) argued the effect of the ascent velocity on the temperature spectrum. They suggested that the distortion in balloon measurements of the temperature spectrum is negligible, provided that the ascent velocity is $\sim 3 \mathrm{~m} / \mathrm{s}$ or larger and the horizontal wind speed is not more than about 10 times the balloon ascent velocity. We examine the balloon measurements and find that our measurements satisfy the two criteria. Thus, in this paper we use the temperature data obtained during the balloon ascent.

On the other hand, Allen and Vincent (1995) discussed in detail the effect of the lag on the temperature spectrum and found that the attenuation of the high wave number range of the spectrum above $20 \mathrm{~km}$ altitude was so large that the spectrum must be corrected for the lag. In order to avoid the correction the temperature data in the lower stratosphere are from below $20 \mathrm{~km}$, where the effect of the lag is small. In addition to this, the temperature data in the troposphere are from above $1.30 \mathrm{~km}$, in order to exclude the planetary boundary layer and other discontinuities, such as obvious frontal boundaries and subsidence inversions. Therefore, we restrict the analysis to the height ranges of $2.90-8.01 \mathrm{~km}$ in the troposphere and $14.65-19.76 \mathrm{~km}$ in the lower stratosphere, which is in rough agreement with those height ranges selected by Nastrom et al. (1997) and Nastrom and VanZandt (2001).

Figure 1a shows an example of the temperature profiles observed in six radiosonde soundings from 13 March to 15 April 2003 during the balloon ascent. It is seen in Fig. 1a that the tropopause level is located at about $11 \mathrm{~km}$, where 
the Brunt-Väisälä frequency squared (i.e. $N^{2}$ ) has a sharp increase with height, as will be seen later.

Another reason for choosing the two height ranges is to ensure a stationary temperature spectrum, since, according to linear saturation model, the vertical wave number spectrum of normalized temperature fluctuations is dependent on $N^{4}$. Therefore, the height ranges in which the Brunt-Väisälä frequency is approximately constant should be used. Figure $1 b$ shows the Brunt-Väisälä frequency squared profile calculated from the temperature profile shown in Fig. 1a. The solid straight lines in Fig. 1b show the mean values of $N^{2}$ and the height ranges used in spectral calculations. Based on the $N^{2}$ structure in Fig. 1b, the mean $N^{2}$ values are $1.44 \times 10^{-4}$ $(\mathrm{rad} / \mathrm{s})^{2}$ in the troposphere $(2.90-8.01 \mathrm{~km})$ and $4.43 \times 10^{-4}$ $(\mathrm{rad} / \mathrm{s})^{2}$ in the lower stratosphere $(14.65-19.76 \mathrm{~km})$.

One potential disadvantage of using the fast Fourier transform technique is the possibility that "leakage" will distort the high-wave number end of the spectrum (Bendat and Piersol, 1971). Recently, Dewan and Grossbard (2000) discussed, in particular the effect of the prewhitening procedure on the temperature spectrum and claimed that the papers by Nastrom et al. (1997) and de la Torre et al. (1997) may contain an artifact in their analyses and should be reexamined using the prewhitening procedure. Unfortunately, nearly all of those previous temperature spectra did not include the prewhitening procedure, except for the recent spectra obtained by Nastrom and VanZandt (2001). This is important to bear in mind when we compare our temperature spectra with other observed spectra. In order to reduce the spectral leakage in this paper we use the prewhitening procedure for our spectral analysis. Prior to the actual spectral analysis, the mean and linear trend of each selected temperature profile is removed. The result of this is then prewhitened, in order to reduce leakage by means of a differentiating filter given by

$y_{i}=x_{i}-\alpha x_{i+1}$,

where $x_{i}$ are the data series before prewhitening, $\alpha$ is taken to be 1 , and $y_{i}$ represents the prewhitened profile. The prewhitened profile (i.e. $T^{\prime}$ ) is further normalized by division by the background temperature profile, $\bar{T}$, so that the analyzed quantity is $T^{\prime} / \bar{T}$. The background temperature profile, $\bar{T}$, is approximated by straight lines fitted by a leastsquares to the individual $T$ profile, as illustrated by the thick solid straight lines in Fig. 1a. A cosine taper window is applied to the normalized temperature profile, following Smith et al. (1985). The normalized temperature profiles are then transformed to the power spectral density using an FFT routine. Finally, the power spectral density is adjusted to compensate for the effect of the differencing and the cosine windowing.

\section{Observational results and discussion}

\subsection{Spectral slopes}

The vertical wave number spectra of normalized temperature fluctuations for six balloon measurements calculated from the method mentioned above are shown in Fig. 2 in the troposphere and in Fig. 3 in the lower stratosphere. We calculate the spectral slopes in the wave number range of $9.77 \times 10^{-4}$ $2.50 \times 10^{-2} \mathrm{cyc} / \mathrm{m}$. The wave number of $2.50 \times 10^{-2} \mathrm{cyc} / \mathrm{m}$ corresponds to half the Nyquist wave number, due to the 10$\mathrm{m}$ resolution. In this wave number range the aliasing effects should be insignificant. At larger wave numbers the expected aliasing effects can be seen in Figs. 2 and 3. The calculated results are given in Table 1. The $N^{2}$ values obtained from six temperature profiles have also been included in Table 1 . The dashed lines in Figs. 2a and 2b are the best fit approximated by a straight line in a log-log plot.

Table 1 shows that the spectral slopes in the wave number ranges of $9.77 \times 10^{-4}-2.5 \times 10^{-2}$ cyc/m vary from -1.73 to -2.03 , with a mean value of -1.88 in the troposphere and from -1.98 to -2.39 , with a mean value of -2.17 in the lower stratosphere. The mean spectral slopes are very different from the value of -3 predicted by current saturation models (Dewan and Good, 1986; Smith et al., 1987; Weinstock, 1990; Hines, 1991; Gardner, 1994; and Dewan, 1997) and from the value of -2.4 predicted by a "universal" atmospheric spectrum model (VanZandt, 1982).

Vertical wave number spectra of normalized temperature fluctuations based on radiosonde measurements in the troposphere and lower stratosphere have been obtained at different stations. Fritts et al. (1988) indicated the excellent agreement of the observed and predicted saturated spectral slopes. Tsuda et al. (1991) analyzed over 2 years of radiosonde data. They found that the mean spectral slopes were very close to -3.0 in the troposphere during the winter and summer and in the lower stratosphere during the winter. However, they also found that the mean spectral slopes varied from -2.16 to -2.40 , with a mean of -2.28 in the lower stratosphere during the summer. Allen and Vincent (1995) reported the -3 slope in the troposphere and the slightly shallower than -3 in the lower stratosphere. All of their spectra were corrected for sensor-response distortion. Nastrom et al. (1997) found the mean slope values of about -3 in the stratosphere and about -2.6 in the troposphere. Pfenninger et al. (1999) obtained the mean slope values of -2.5 in the troposphere and -2.4 in lower stratosphere. Following Dewan and Grossbard (2000), Nastrom and VanZandt (2001) used the prewhitening procedure to reexamine their previous data and found the mean spectral slope values of about -2.9 in the troposphere and about -3.0 in the lower stratosphere. If we compare our spectral slopes with these earlier observational results, we find that our observed spectral slopes are not only much shallower than these earlier results 

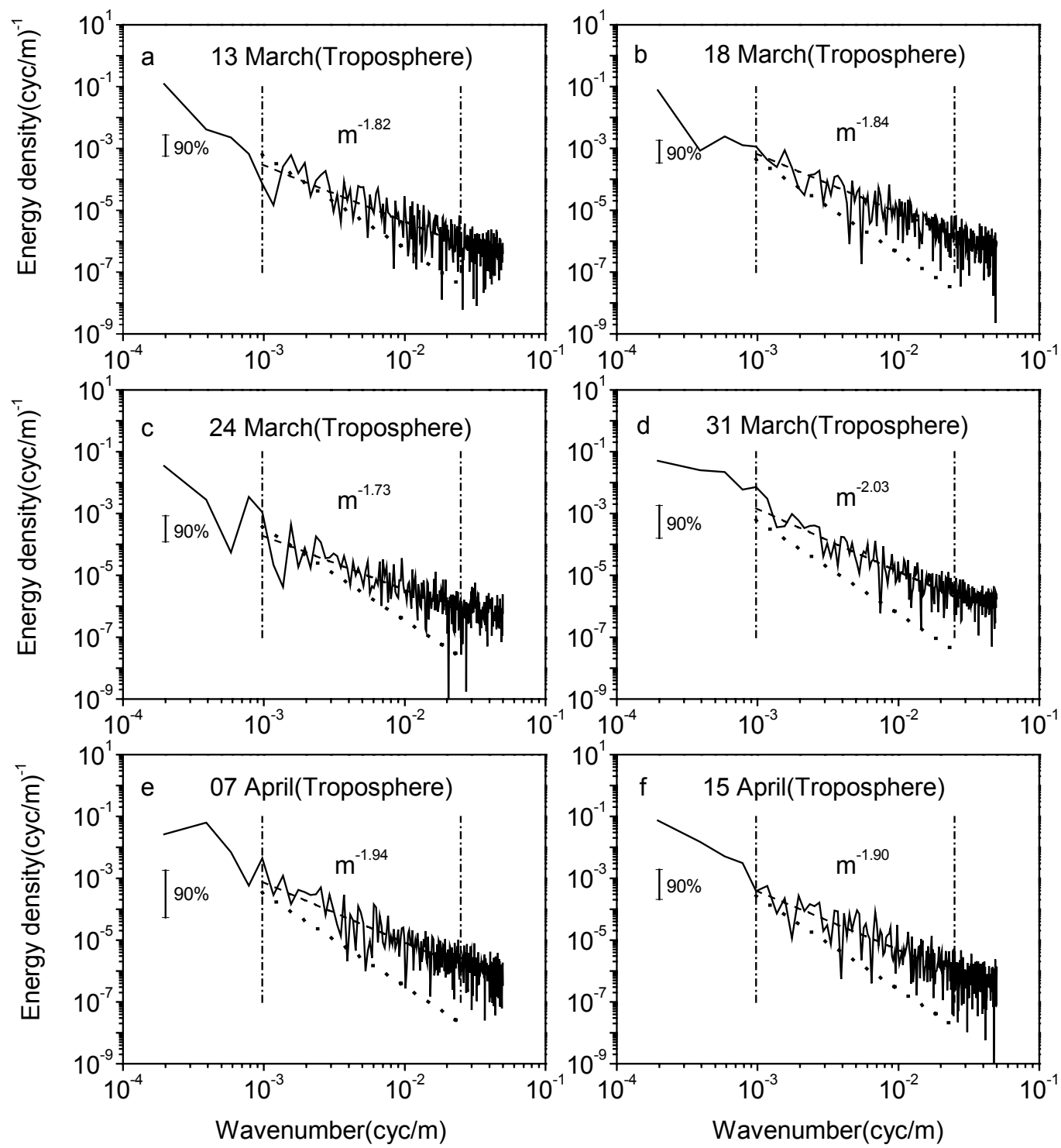

Fig. 2. Vertical wave number spectra of normalized temperature fluctuations observed in the troposphere. The dashed lines are the best fit approximately by a straight line. The thick dotted straight lines show the saturated spectral amplitudes predicted by Eq. (2). The confidence intervals for the $90 \%$ level are given in these figures by the vertical intervals.

but are believed to be the shallowest slopes ever measured by balloon-borne radiosonde soundings.

\subsection{Spectral amplitudes}

Many observed temperature spectra (Fritts et al., 1988; Tsuda et al., 1991; Allen and Vincent, 1995; Nastrom et al., 1997; de la Torre et al., 1997; and Nastrom and VanZandt, 2001) have been referred to in the simple model of saturated spectra derived by Smith et al. (1987):

$F_{T}^{s}(m)=d\left(\frac{N^{2}}{g^{2}}\right) \frac{N^{2}}{m^{3}}$, where $d \approx 1 / 10, N^{2}$ is the background Brunt-Väisälä frequency squared, which has been obtained from the temperature profiles, and $g$ is the acceleration due to gravity. The thick dotted lines in Fig. 2 and Fig. 3 indicate the saturated spectral amplitudes with different values of $N^{2}$ predicted by Eq. (2) in the wave number range of $9.77 \times 10^{-4}$ $2.50 \times 10^{-2} \mathrm{cyc} / \mathrm{m}$. At $m=1 /(100 \mathrm{~m})$ the observed spectral amplitudes and the predicted saturated spectral amplitudes with different values of $N^{2}$ are given in Table 1 , which reveals that the mean spectral amplitudes at $m=1 /(100 \mathrm{~m})$ are about 17 times larger in the troposphere and about 4 times larger in the lower stratosphere than the predicted saturated spectral amplitudes. These data clearly show that the ob- 

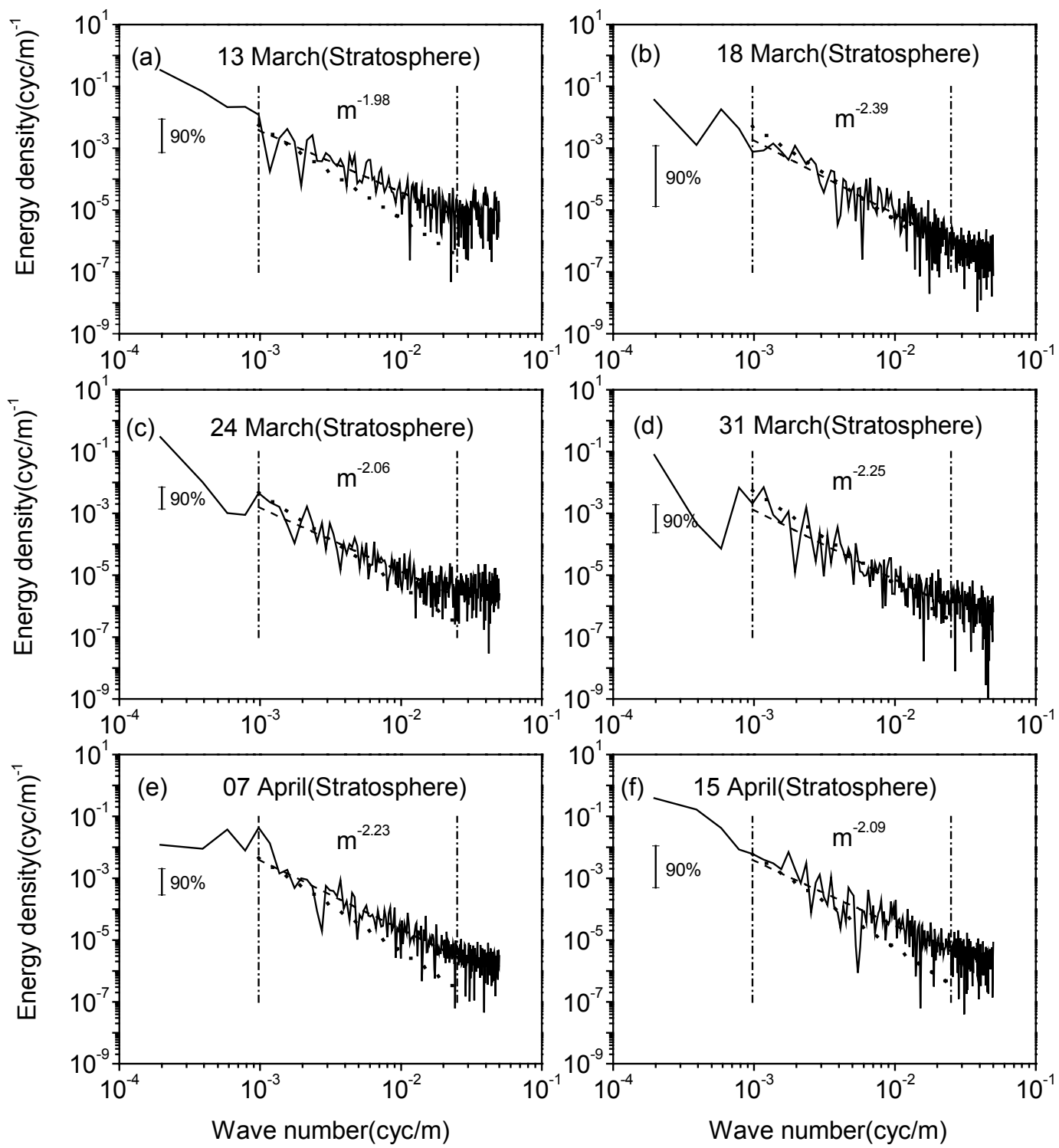

Fig. 3. As in Fig. 2, but for balloon measurements in the lower stratosphere.

served spectral amplitudes are not only in considerable disagreement with predicted saturated amplitudes by the Smith et al. (1987) model but differ considerably with earlier observational results of Fritts et al. (1988), Tsuda et al. (1991), Allen and Vincent (1995), and Nastrom et al. (1997), because the mean spectral amplitudes obtained by these studies either were consistent with the predicted saturated amplitudes or were larger than the predicted saturated amplitudes, often by as much as a factor of about 3 .

The mean amplitudes larger than the predicted saturated amplitudes, together with the much shallower slopes, collectively show that our observed spectra do not obey current saturation models or the "universal" atmospheric spectrum model, in both slope and amplitude. Clearly, more observa- tional data and studies are required in order to be able to draw statistical interpretations.

We also consider another theory developed by Echermann (1995), in which attenuated spectra arise due to changes in background wind speeds. In order to explain the vertical wavenumber power spectra of wind and normalized temperature fluctuations in both amplitude and slope occurring in the stratosphere and mesosphere, Eckermann (1995) introduced a sign parameter:

$\beta=\operatorname{sgn}\left(\frac{\frac{d}{d z} \bar{U}}{c_{h}-\bar{U}}\right)$,

where $\bar{U}$ is mean zonal wind speed, $c_{h}$ is the ground-based horizontal phase speed. If we know the vertical profile of the 
Table 1. Spectral slope and amplitude obtained from balloon soundings.

\begin{tabular}{|c|c|c|c|c|}
\hline $\begin{array}{l}\text { Profile } \\
\text { Troposphere } \\
(2.90-8.01 \mathrm{~km})\end{array}$ & $\begin{array}{l}N^{2} \\
(\mathrm{rad} / \mathrm{s})^{2}\end{array}$ & Slope & $\begin{array}{l}\text { Amplitude } \\
\text { at } m=(1 / 100 \mathrm{~m}) \\
(\mathrm{cyc} / \mathrm{m})^{-1}\end{array}$ & $\begin{array}{l}\text { Model amplitude } \\
\text { at } m=(1 / 100 \mathrm{~m}) \\
(\mathrm{cyc} / \mathrm{m})^{-1}\end{array}$ \\
\hline 13 March & $1.44 \times 10^{-4}$ & -1.82 & $4.31 \times 10^{-6}$ & $5.47 \times 10^{-7}$ \\
\hline 18 March & $1.23 \times 10^{-4}$ & -1.84 & $6.89 \times 10^{-6}$ & $3.99 \times 10^{-7}$ \\
\hline 24 March & $1.19 \times 10^{-4}$ & -1.73 & $4.43 \times 10^{-6}$ & $3.73 \times 10^{-7}$ \\
\hline 31 March & $1.49 \times 10^{-4}$ & -2.03 & $1.32 \times 10^{-5}$ & $5.86 \times 10^{-7}$ \\
\hline 7 April & $1.11 \times 10^{-4}$ & -1.94 & $8.37 \times 10^{-6}$ & $3.25 \times 10^{-7}$ \\
\hline 15 April & $9.71 \times 10^{-5}$ & -1.90 & $4.81 \times 10^{-6}$ & $2.49 \times 10^{-7}$ \\
\hline Mean & $1.24 \times 10^{-4}$ & -1.88 & $7.00 \times 10^{-6}$ & $4.13 \times 10^{-7}$ \\
\hline $\begin{array}{l}\text { Profile } \\
\text { Stratosphere } \\
(14.65-19.76 \mathrm{~km})\end{array}$ & $\begin{array}{l}N^{2} \\
(\mathrm{rad} / \mathrm{s})^{2}\end{array}$ & Slope & $\begin{array}{l}\text { Amplitude } \\
\text { at } m=(1 / 100 \mathrm{~m}) \\
(\mathrm{cyc} / \mathrm{m})^{-1}\end{array}$ & $\begin{array}{l}\text { Model amplitude at } \\
m=(1 / 100 \mathrm{~m}) \\
(\text { cyc/m })^{-1}\end{array}$ \\
\hline 13 March & $4.43 \times 10^{-4}$ & -1.98 & $3.79 \times 10^{-5}$ & $5.18 \times 10^{-6}$ \\
\hline 18 March & $4.27 \times 10^{-4}$ & -2.39 & $7.27 \times 10^{-6}$ & $4.81 \times 10^{-6}$ \\
\hline 24 March & $4.10 \times 10^{-4}$ & -2.06 & $1.32 \times 10^{-5}$ & $4.43 \times 10^{-6}$ \\
\hline 31 March & $4.38 \times 10^{-4}$ & -2.25 & $7.16 \times 10^{-6}$ & $5.06 \times 10^{-6}$ \\
\hline 7 April & $3.85 \times 10^{-4}$ & -2.23 & $2.20 \times 10^{-5}$ & $3.91 \times 10^{-6}$ \\
\hline 15 April & $4.55 \times 10^{-4}$ & -2.09 & $2.98 \times 10^{-5}$ & $5.46 \times 10^{-6}$ \\
\hline Mean & $4.26 \times 10^{-4}$ & -2.17 & $1.96 \times 10^{-5}$ & $4.81 \times 10^{-6}$ \\
\hline
\end{tabular}

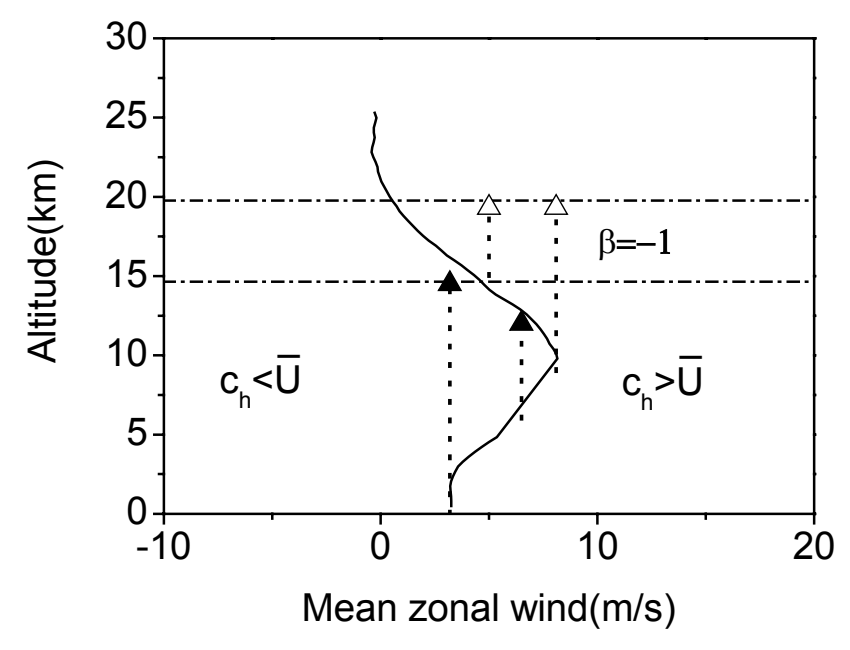

Fig. 4. Mean zonal wind profile observed during March and April 2003 over the Beijing Meteorological Observatory (solid line). Upward pointing triangles represent upward propagating waves. The open triangles represent waves for which $c_{h}>\bar{U}$, whereas the solid triangles represent $c_{h}<\bar{U}$ waves.

mean zonal wind speed and the horizontal phase speed, we can determine the sign of $\beta$. Eckermann's theory predicts reduced spectral density and a shallower spectral slope when the mean zonal wind changes yield $\beta=-1$ (hereinafter referred to as downshifting), whereas conventional $\alpha \mathrm{A}(\mathrm{N}) \mathrm{m}^{-3}$ spectra are anticipated when the mean zonal wind changes are smaller or yield $\beta=0$ or $\beta=+1$ (hereinafter referred to as upshifting).

Following Eckermann (1995), we choose $c_{h}=25 \mathrm{~m} / \mathrm{s}$ and use the mean zonal wind profile measured during these flights to determine the sign of $\beta$. The result of this analysis is shown in Fig. 4. The solid line and the height range between the two dot-dashed lines in Fig. 4 are the mean zonal wind profile and the height interval of spectral analysis, respectively. We consider $c_{h}-\bar{U}>0$ waves. In this case, the $c_{h}-\bar{U}>0$ waves, together with the decrease in the mean zonal wind with height, in the height interval of spectral analysis, act collectively to produce $\beta=-1$ (downshifting). On the other hand, the observations have shown that gravity waves are also produced near the jet stream peak at $\sim 10 \mathrm{~km}$ (Yamanaka et al., 1989; Fritts and Nastrom, 1992; Sato, 1994), and these waves can enter the stratosphere where they yield $\beta=-1$ (downshifting). However, the lower tropospheric waves cannot enter the stratosphere due to criticallevel encounters lower down. These results for $\beta=-1$ (downshifting) are illustrated in Fig. 4 with open triangles. Conversely, the $c_{h}-\bar{U}<0$ waves, such as mountain waves (e.g. $c_{h} \approx 0$ ), cannot propagate into the height interval of spectral analysis due to critical-level encounters lower down, as shown by the solid triangles in Fig. 4.

Thus, during March and April, the mean zonal wind structure in Fig. 4 yields downshifting $(\beta=-1)$. In this case, the wind-shifting model predicts a spectral slope of $q<3$. This is consistent with the mean slope $q \approx 2.08$ observed in the lower 
stratosphere. The mean spectral amplitude at $m=1 /(100 \mathrm{~m})$ in Table 1 is about 4 times larger than the predicted saturated spectral amplitude measured in the lower stratosphere. This shows that the mean spectrum has enhanced spectral density, whereas the wind-shifting model predicts reduced spectral density. Clearly, in order to explain well the observed spectral amplitude, further study of the wind-shifting model is required.

\section{Conclusions}

We have presented a spectral analysis of six temperature profiles with a height resolution of $10 \mathrm{~m}$ measured in the troposphere and lower stratosphere during March and April 2003 over the Beijing Meteorological Observatory. This resolution allows us to study temperature spectra up to higher wave numbers than many published papers. The mean spectral slopes are approximately -1.9 in the troposphere and -2.2 in the lower stratosphere. The mean spectral amplitudes at $m=1 /(100 \mathrm{~m})$ are approximately 17 times larger in the troposphere and 4 times larger in the lower stratosphere than the predicted saturated spectral amplitudes. These results clearly show that our observed spectra do not obey current saturation models, the "universal" atmospheric spectrum model, or the wind-shifting model, in both slope and amplitude. Therefore further observational and theoretical studies are required in order to be able to explain well the observed spectra in both slope and amplitude.

Acknowledgements. This study was supported by the National Natural Science Foundation of China (grants 40225011 and 40336054), National Research Project (G2000078407), and Major Project of Chinese Academy of Sciences (CAS) (KZCX3-SW-217). This work was supported in part by the International Collaboration Research Tem Program of the Chinese Academy of Sciences.

Topical Editor U. P. Hoppe thanks M. Friedrich and S. Eckermann for their help in evaluating this paper.

\section{References}

Allen, S. J. and Vincent R. A.: Gravity wave activity in the lower atmosphere: Seasonal and latitudinal variations, J. Geophys. Res., 100, 1327-1350, 1995.

Barat, J. and Cot, C.: Wind shear rotary spectra in the atmosphere, Geophys. Res. Lett., 19, 103-106, 1992.

Bendat, J. S. and Piersol, A. G.: Random Data: Analysis and Measurement Procedures, Wiley \& Son, 286-343, 1971.

Bian, J. C., Chen, H. B., and Lu, D. R.: Statistics of gravity waves in the lower stratosphere over Beijing based on high vertical resolution radiosonde, Science in China, Series D 48(9), 1548-1558, 2005.

de la Torre, A., Alexander, P., and Giraldez, A.: High-resolution temperature profiles measured with stratospheric balloons near the Andes Mountains, Geophys. Res. Lett., 24, 1079-1082, 1997.
Dewan, E. M., Grossbard, N., Quesada, A. F., and Good, R. E.: Spectral analysis of $10 \mathrm{~m}$ resolution scalar velocity profiles in the stratosphere, Geophys. Res. Lett., 11, 80-83, 1984.

Dewan, E. M. and Good, R. E.: Ssturation and the "universal" spectrum for vertical profiles of horizontal scalar winds in the atmosphere, J. Geophys. Res., 91, 2742-2748, 1986.

Dewan, E. M.: Saturated-cascade similitude theory of gravity wave spectra, J. Geophys. Res., 102, 29 799-29 817, 1997.

Dewan, E. M. and Grossbard, N.: Power spectral artifacts in published balloon data and implications regarding saturated gravity wave theories, J. Geophys. Res., 105, 4667-4683, 2000.

Eckermann, S. D.: Effect of background winds on vertical wavenumber spectra of atmospheric gravity waves, J. Geophyys. Res., 100, 14 097-14 112, 1995.

Endlich, R. M., Singleton, R. C., and Kaufman, J. W.: Spectral analysis of detailed vertical wind speed profiles, J. Atmos. Sci., 26, 1030-1041, 1969.

Fritts, D. C. and Chou, H. G.: An investigation of the vertical wavenumber and frequency spectra of gravity wave motions in the lower stratosphere, J. Atmos. Sci., 44, 3610-3624, 1987.

Fritts, D. C., Tsuda, T., Sato, T., Fukao, S., and Kato, S.: Observational evidence of a saturated gravity wave spectrum in the troposphere and lower stratosphere, J. Atmos. Sci., 45, 1741-1759, 1988.

Fritts, D. C. and Nastrom, G. D.: Sources of mesoscale variability of gravity wave, II, Frontal, convective, and jet stream excitation, J. Atmos. Sci., 49, 111-127, 1992.

Gardner, C. S.: Diffusive filtering theory of gravity wave spectra in the atmosphere, J. Geophys. Res., 99, 20 601-20 622, 1994.

Gardner, C. S. and Gardner, N. F.: Measurements distortion in aircraft, space shuttle, and balloon observations of atmospheric density and temperature perturbation spectra, J. Geophys. Res., 98, 1023-1033, 1993.

Garrett, C. and Munk, W.: Space-time scales of internal waves: A progress report, J. Geophy. Res., 80, 291-297, 1975.

Hines, C. O.: The saturation of gravity waves in the middle atmosphere, II, Development of Doppler-spread theory, J. Atmos. Sci., 48, 1360-1379, 1991.

Nastrom, G. D., VanZandt, T. E., and Warnock, J. M.: Vertical wavenumber spectra of wind and temperature from highresolution balloon soundings over Illinois, J. Geophys. Res., 102, 6685-6701, 1997.

Nastrom, G. D. and VanZandt, T. E.: Seasonal variability of the observed vertical wave number spectra of wind and temperature and the effects of prewhitening, J. Geophys. Res., 106, 14369 $14375,2001$.

Pfenninger, M., Liu, A. Z., Papen, G. C., and Gardner, C. S.: Gravity wave characteristics in the lower atmosphere at south pole, J. Geophys. Res., 104, 5963-5984, 1999.

Sato, K.: A statistical study of the structure, saturation and sources of inertio-gravity waves in the lower stratosphere observed with the MU radar, J. Atmos. Terr. Phys., 56, 755-774, 1994.

Senft, D. C. and Gardner, C. S.: Seasonal variability of gravity wave activity and spectra in the mesopause region at Urbana, J. Geophys. Res., 96, 17 229-17 264, 1991.

Senft, D. C., Hostetler, C. A., and Gardner, C. S.: Characteristics of gravity wave activity and spectra in the upper stratosphere and upper mesosphere at Arecibo during early April 1989, J. Atmos. Terr. Phys., 55, 425-437, 1993. 
Smith, S. A., Fritts, D. C., and VanZandt, T. E.: Comparison of mesospheric wind spectra with a gravity wave model, Radio Sci., 20, 1331-1338, 1985.

Smith, S. A., Fritts, D. C., and VanZandt, T. E.: Evidence of a saturation spectrum of atmospheric gravity waves, J. Atmos. Sci., 44, 1404-1410, 1987.

Tsuda, T., Inoue, T., Fritts, D. C., VanZandt, T. E., Kato, S., Sato, T., and Fukao, S.: MST radar observations of a saturated gravity wave spectrum, J. Atmos. Sci., 46, 2440-2447, 1989.

Tsuda, T., VanZandt, T. E., Mizumoto, M., Kato, S., and Fukao, S.: Spectral analysis of temperature and Brunt-Väisälä frequency fluctuations observed by Radiosondes, J. Geophys. Res., 96, 17 265-17 278, 1991.
VanZandt, T. E.: A universal spectrum of buoyancy waves in the atmosphere, Geophys. Res. Lett., 9, 575-578, 1982.

Weinstock, J.: Saturated and unsaturated spectra of gravity waves and scale-dependent diffusion, J. Atmos. Sci., 47, 2211-2225, 1990.

Wu, Y. F. and Widdel, H. U.: Saturated gravity wave spectrum in the polar lower thermosphere observed by foil chaff during campaign "Sosium 88”, J. Atmos. Sci., 49, 1781-1789, 1992.

Yamanaka, M. D., Fukao, S., Matsumoto, H., Sato, T., Tsuda, T., and Kato, S.: Internal gravity wave selection in the upper troposphere and lower stratosphere observed by the MU radar, Pure Appl. Geophys., 130, 481-495, 1989. 